\title{
Sleep disorders and main determinants among hospital staffs in a referral hospital in Iran
}

\author{
Zahra Fotokian $^{1}$, Reza Ebrahimi $\operatorname{Rad}^{2 * \mathbb{(}}$, Masume Asghari Valujai $^{3}$ \\ ${ }^{1}$ Nursing Care Research Center, School of Nursing and Midwifery, Babol University of Medical Sciences, Babol, Iran \\ 2Department of Neurology, Tonekabon Branch, Islamic Azad University, Tonekabon, Iran \\ ${ }^{3}$ Tonekabon Branch, Islamic Azad University, Tonekabon, Iran
}

\section{Correspondence to: \\ Reza Ebrahimi Rad, \\ Email: reza_er_neuro@yahoo. com}

Received: 13 Jan. 2021 Accepted: 7 Mar. 2021

ePublished: 18 May 2021

Keywords: Sleep, Disorders, Hospital staffs

\begin{abstract}
Introduction: The prevalence rate of sleep disorders among hospital staff is expected to high due to shift work and its related circadian cycle disturbance. Complexity, high prevalence, and health implications related to sleep disorders are of great importance.

Objectives: The present study aimed to assess the prevalence and main determinants of sleep disorders among hospital staff.

Patients and Methods: This cross-sectional study was performed on 200 head nurses, nurses, midwives, operating room technicians, health care providers, service staffs of all departments, and physicians at Shaheed Rajaei hospital in Tonekabon city, Iran in 2015. The questionnaire which assessed the sleep disturbances was sourced from four scaling systems of Global Sleep Assessment Questionnaire (GSAQ), insomnia severity index (ISI), Pittsburgh Sleep Quality Index (PSQI), and Fatigue Severity Scale (FSS). Results: According to the assessment by the study adopted questionnaire, $78 \%(78.6 \%$ of males and $77.8 \%$ of females) suffered from work-related sleep disorders. Regarding association between work shifts and likelihood of sleep disorders, it was shown a significantly higher rate of sleep disturbances in the staffs with morning and evening shifts (100\%), morning and night shifts (100\%), or evening and night shifts (100\%), simultaneously $(P<0.001)$. Marital status, work experience, and gender could not affect sleep quality. Conclusion: Most of the hospital staff especially practical nurses and nurses suffered from sleep disturbances. Simultaneous and multi-sectional work shifts lead to higher likelihood of sleep problem among staffs.
\end{abstract}

\begin{abstract}
Citation: Fotokian Z, Ebrahimi Rad R, Asghari Valujai M. Sleep disorders and main determinants among hospital staffs in a referral hospital in Iran. J Prev Epidemiol. 2021;6(1):e01. doi: 10.34172/jpe.2021.01.
\end{abstract}

\section{Introduction}

In all clinical setting, round-the-clock performance is now the main occupational schedule. In other words, shift work is a standard program in health system staff. However, in reality, it is a non-standard schedule in general because of related physical and even psychological problems such as chronic fatigues, increased cardiovascular diseases likelihood, depression and anxiety, or even sleep disorders (1-5). The appearance of such disorders depends directly on toleration, personality trait, work load, hardiness, and demographic characteristics of staff (6). In this regard, the frequency of sleep disorders among hospital staffs is expected to be high due to shifting work and its related circadian cycle disturbance (4). Sleep disorders in hospital staff are mainly characterized by sleepiness and insomnia which is attributed to work-related schedule, leading sleeptime misalignment. These symptoms may lead to physical or mental disorders or even

\begin{abstract}
Key point
In a cross-sectional study performed on 200 head nurses, nurses, midwives, operating room technicians, health care providers, service staffs of all departments, and physicians in Tonekabon city, we found that most of the hospital staff especially practical nurses and nurses suffered from sleep disturbances.
\end{abstract}

unusual medication use (7). The incidence of sleep disorders varies from about $25 \%$ to $40 \%$ among general Asian population (8). Sleep disorders in these people usually begin after night shift and continue with a feeling of tiredness, sleepiness or insomnia, reduced mental capacity and importance in doing things. Continuity of these symptoms in everyday life of a person and its unrestrictedness to the day after night shift would reduce its efficiency and ability to do work and social work (9-11). It is an important issue that many staff of hospitals and also clinicians are completely unaware of the consequences of sleep disorders due to 
their work shifts and thus they do not care about this entity (12). These individuals experience significant negative health consequences and diminished quality of life as a result of shift work. Furthermore, at the social level, sleep disorder is dealing with dramatically increased accident risk and financial costs for staff.

\section{Objectives}

Given the high prevalence of sleep disorders in health care workers, especially those working in night shifts, and the risks to the health of these employees, as well as the possibility of injury due to their reduced efficiency for patients, the present study assessed the prevalence and main determinants of sleep disorders among hospital staffs in a sample hospital in Iran.

\section{Patients and Methods \\ Study design}

This cross-sectional study was carried out on head nurses, nurses, midwives, operating room technicians, health care providers, service staffs of all departments, and physicians at Shaheed Rajaei hospital in Tonekabon city, Iran in 2015. Clinic clerks, administrative staff and those who are suffering from sleep disorders or sleep disorders caused by neurological and medical illnesses or having history of substance use were all excluded. The study questionnaire was given to the subjects. This questionnaire including demographic information, a complex of information on sleep disturbances, factors affecting participants' sleep status and the state of shifts and work schedules. Moreover the questionnaire which assessed the sleep disturbances was sourced from three scaling systems of Global Sleep Assessment Questionnaire (GSAQ), and Pittsburgh Sleep Quality Index (PSQI). The GSAQ comprises 11 items includes questions regarding age, gender, height, weight, and employment status. The 11 items are about life activities, mood and medical issues as they relate to sleep, along with symptoms associated with insomnia, obstructive sleep apnea, restless legs syndrome/periodic limb movement, and parasomnias. The PSQI assesses sleep quality. The final questionnaire adopted from the three tools consisted of 17 items graded from 0-4 that the final score higher than 32 represented sleep disorder in staffs. The reliability of these questionnaires was confirmed in the same studies with Cronbach's alpha $>0.75(3,5,12)$. The questionnaires were completed by samples.

\section{Ethical issues}

The research followed the tenets of the Declaration of Helsinki. The Ethics Committee of Tonekabon Branch, Islamic Azad University approved this study (IR.IAU.TON. REC.1399.064). Accordingly, written informed consent was taken from all participants before any data collection.

\section{Data analysis}

The data were analyzed through SPSS version 23.0 for
Windows. Sleep scores were calculated using the indices including normality tests (Shapiro-Wilk) and the following tests were performed; chi-square test and Mann-Whitney $\mathrm{U}$ test. The logistic regression test was used to determine the predictors of sleep disorders in staff. The significance level was considered less than 0.05 .

\section{Results}

Totally, 200 subjects were included in the present assessment. Of 200 staff included, $72 \%$ were female and $28 \%$ were male. The majority of staff $(47 \%)$ were nurses, $17 \%$ were physicians, and $15 \%$ were service staff. More than half of the subjects (57\%) had work experience of less than 5 years. Half of the staff $(51 \%)$ had circulating work shifts, while $20 \%$ had night shifts. Additionally, 56\% were single and $44 \%$ were married (Table 1). According to the assessment by the study adopted questionnaire, $78 \%$ suffered from work-related sleep disorders. In total, $78.6 \%$ of male and $77.8 \%$ of female subjects suffered sleep disorders without significant difference $(P=0.90)$. Considering different occupational levels of staffs showed that the highest prevalence rate of sleep disorders was specified to practical nurses (100\%) followed by nurses $(85.1 \%)$, while the lowest rate of disorders was revealed in physicians (52.9\%) with a significant difference $(P<0.001)$. Work experience could not be an indicator for appearing sleep disorders that the frequency of sleep

Table 1. Study sample demographics

\begin{tabular}{lc}
\hline Variables & No. $(\%)$ \\
\hline Gender & $144(72.0)$ \\
Male & $56(28.0)$ \\
Female & \\
Job position & $14(7.0)$ \\
Practical nurse & $94(47.0)$ \\
Nurse & $12(6.0)$ \\
Surgical room technician & $30(15.0)$ \\
Service staffs & $34(17.0)$ \\
Physician & $8(4.0)$ \\
Midwifery & $8(4.0)$ \\
Hospital keeper & \\
Work experience & $114(57.0)$ \\
Less than 5 years & $58(29.0)$ \\
5-10 years & $16(8.0)$ \\
11-20 years & $12(6.0)$ \\
More than 20 years & \\
\hline Work shift & $6(3.0)$ \\
\hline Morning & $6(30(15.0)$ \\
Evening & $10(5.0)$ \\
Night & $40(20.0)$ \\
Morning-evening & $6(56.0)$ \\
Morning-night & \\
Rotatory & \\
Marital status & \\
Married & \\
\hline & \\
\hline
\end{tabular}


disorders in those with experience less than 5 years, 5-10 years, 11-20 years, and more than 20 years was $75.4 \%$, $79.3 \%, 87.5 \%$, and $83.3 \%$ respectively. It is concluded; it is no significant difference between work experience and sleep disorders $(P=0.67)$. Regarding association between work shifts and likelihood of sleep disorders, it was shown significantly higher rate of sleep disturbances in the staffs with rotational shifts as morning-evening, morning-night, evening-night simultaneously. There was a significant difference between work shift and sleep disorders $(P<0.001)$ (Table 2$)$. Additionally, $72.7 \%$ of single staff and $84.1 \%$ of married staff suffered from sleep disorders with no significant difference $(P=0.31$; Table 1$)$. The results showed that there is a significant difference between some parameters of GSAQ and PSQI. There was a significant correlation between life activities, insomnia, restless legs syndrome, obstructive sleep apnea, and parasomnias with PSQI $(P<0.05)$. However, there was no significant correlation between mood status with PSQI $(P=0.59$; Table 3).

\section{Discussion}

According to the present study, work shift (night shift) and having two shifts spontaneously (morning-night, eveningnight) can adversely affect sleep status leading increased likelihood of sleep disorders among staff. The study by Shao

Table 2. Prevalence of sleep disorders based on characteristics

\begin{tabular}{|c|c|c|c|}
\hline Item & $\begin{array}{c}\text { With sleep } \\
\text { disorders }\end{array}$ & $\begin{array}{c}\text { Without sleep } \\
\text { disorders }\end{array}$ & $P$ value \\
\hline Gender & & & 0.90 \\
\hline Male & $44(28.3)$ & $12(27.3)$ & \\
\hline Female & $112(71.7)$ & $32(72.7)$ & \\
\hline Job position & & & 0.004 \\
\hline Practical nurse & $14(9.0)$ & $0(0.0)$ & \\
\hline Nurse & $80(51.3)$ & $14(31.8)$ & \\
\hline Surgical room technician & $8(5.1)$ & $4(9.1)$ & \\
\hline Service staffs & $24(15.5)$ & $6(13.7)$ & \\
\hline Physician & $18(11.5)$ & $16(36.4)$ & \\
\hline Midwifery & $6(3.8)$ & $2(4.5)$ & \\
\hline Hospital keeper & $6(3.8)$ & $2(4.5)$ & \\
\hline Work experience & & & 0.67 \\
\hline$<5$ years & $86(55.1)$ & $28(63.6)$ & \\
\hline $5-10$ years & $46(29.5)$ & $12(27.4)$ & \\
\hline $11-20$ years & $14(9.0)$ & $2(4.5)$ & \\
\hline$>20$ years & $10(6.4)$ & $2(4.5)$ & \\
\hline Work shift & & & $<0.001$ \\
\hline Morning & $4(2.6)$ & $2(4.5)$ & \\
\hline Evening & $4(2.6)$ & $2(4.5)$ & \\
\hline Night & $36(23.1)$ & $4(9.1)$ & \\
\hline Morning-evening & $6(3.8)$ & $0(0.0)$ & \\
\hline Morning-night & $30(19.2)$ & $0(0.0)$ & \\
\hline Evening-night & $10(6.4)$ & $0(0.0)$ & \\
\hline Rotatory & $66(42.3)$ & $36(81.9)$ & \\
\hline Marital status & & & 0.31 \\
\hline Married & $92(59.0)$ & $20(45.5)$ & \\
\hline Singles & $64(41.0)$ & $24(54.5)$ & \\
\hline
\end{tabular}

Table 3. Correlation between GSAQ and PSQI

\begin{tabular}{lccl}
\hline \multirow{2}{*}{ GSAQ parameters } & \multicolumn{3}{c}{ PSQI score } \\
\cline { 2 - 4 } & $\boldsymbol{\beta}$ & $\boldsymbol{r}$ & $\boldsymbol{P}$ value \\
\hline Mood & 0.003 & 0.04 & 0.59 \\
Life activities & -0.03 & 0.17 & 0.03 \\
Insomnia & 1.27 & 0.20 & 0.01 \\
Obstructive sleep apnea & 0.045 & 0.32 & 0.006 \\
$\begin{array}{l}\text { Restless legs syndrome (periodic limb } \\
\text { movement) }\end{array}$ & 0.32 & 0.035 & 0.047 \\
Parasomnias & 0.076 & 0.35 & 0.002 \\
\hline
\end{tabular}

et al confirmed the relationship between sleep quality with shift work in nurses (8). In other words, paying attention to this issue and planning to reduce staff workload and increase work efficacy is very important. In this regard, it should be planned the work shift only as a single shift to both minimizing the work capacity and minimizing work errors. Sleep disorders have a major influence on nurses' quality of life and their health status. In fact, reducing sleep quality in hospital staff can negatively affect the load of activities in workers with rotational shift, particularly with respect to their personal health status and thus to social functioning. Nevertheless, fortunately, in most clinical settings particularly in developing countries, this issue is completely ignored (10).

The results showed; most of nurses (51.1\%) suffered from work-related sleep disorders. In a study conducted by Gallup institute (13), all practical nurses and $85 \%$ of nurses had different degrees of sleep disorders. The results showed that as many as $58 \%$ of participants experience some kinds of sleep problems during the year, whereas $24 \%$ of participants have insomnia. Some experts have found that the prevalence of sleep disorders among patients in primary health care is $69 \%$ near to the sleep disorders among healthcare workers. In a study by EstrynBehar et al (14), about $31 \%$ of nurses suffered from sleep problems, therefore when the woman's sleep is less than six hours on workdays, she had regular sleep problems on workdays, and had regular sleep problems on rest days, or if she described at least two of these situations. The only association observed with shift was a higher proportion of sleep problems among nurses working at night. Recent studies have emphasized high load of sleep disorders among hospital workers especially among professionals. In a study by Alshahrani et al (15), the Sleep Quality Index was significantly higher in shift work health care providers and they concluded that the shift work among health care professionals is associated with poor sleep quality. In Korsiak and colleagues' survey (16), all type shift workers had 20-30 minutes sleep less than just day shift workers leading to sleep disorder in night shift workers. Additionally, comparing work shift-related sleep disorders in healthcare workers in western and eastern countries showed higher rate of these problems in eastern nations indicating different work planning schedules in different 
countries. In a study conducted by Ghalichi et al in Iran (17), $43.1 \%$ of nurses were bad sleepers predicted with female sex, divorced, shift-working, and advanced age factors.

Demographic properties can impact sleep status as well. The most well studied of these factors is age. Researchers suggest that older shift workers have more less sleep time compared with younger shift workers (18), and report higher levels of excessive sleepiness as a result of shift work (19). Insomnia is also correlated with age and it is obvious that increased vulnerability following aging is due to changes impacting the homeostatic and circadian sleepwake systems. In addition age, effect of gender has also been evaluated in relation to Sleep disturbances. Although most sleep disturbances research has been conducted among males, female shift workers present slightly less sleep time, and psychological distress (20). However it is not clear whether these differences are due to genderrelated differences in sleep, expected roles upon returning home, or other reasons.

In the present study, nurses have more poor quality of sleep compared to other staff. Moreover, nurses with high level of education had a much higher risk of sleep disorder. In the study by Chien et al (21), 75.8\% did not have nor enough sleep. Nurses, who had low level of education, were more at risk of sleep disorder compared to nurses with a college or higher education level.

In this study, shifting in two periods of the day can effectively increase the risk for sleep deficits. In other words, number of working hours and disturbances in boarding cycle may affect the sleep quality in staff. Previous studies presented shift work as one of the major causes of poor sleep quality among nurses $(22,23)$, which were inconsistent with our results.

In conclusion, most of the hospital staff especially practical nurses and nurses suffered from sleep disturbances. Simultaneous and multi-sectional work shifts lead to higher likelihood of sleep problem among staff. The results of other studies on overall prevalence of sleep disorders among hospital workers are contradictory due to different working schedules, employing different tools for assessing sleep quality and quantity, as well as personal and even social differences.

The present study revealed that is correlation between some parameters of GSAQ and PSQI. It is significant differences between Life activities, Insomnia, Obstructive Sleep Apnea, restless legs syndrome, and parasomnias with PSQI. These conclusions were consistent with the study by Chien et al (21).

\section{Conclusion}

The present study showed that most of the hospital staff especially practical nurses and nurses suffered from sleep disturbances. Simultaneous and multi-sectional work shifts lead to higher likelihood of sleep problem among staff. It is suggested to perform further research on this subject with larger sample size.

\section{Study limitations}

During the research, we encountered some problems such as inconsistencies in implementation and time constraints.

\section{Acknowledgments}

The authors wish to thank Rasool Akram Medical Complex Clinical Research Development Center (RCRDC), Iran University of Medical Sciences for technically supported implementation of the project.

Authors' contribution

FZ and ERR designed the study, observed accuracy and validity of the study. AVM collected the data. ERR supervised the project. FZ and ERR wrote the paper. All authors edited and revised the final manuscript and accepted its publication.

Conflicts of interest

The authors declared no competing interests.

Ethical considerations

Ethical issues including plagiarism, double publication, and redundancy have been completely observed by the authors.

\section{Funding/Support}

The authors declare that there is no source of funding for the research reported.

\section{References}

1. Pavlova M. Circadian Rhythm Sleep-Wake Disorders. Continuum (Minneap Minn). 2017;23:1051-1063.. doi: 10.1212/ CON.0000000000000499.

2. Huon LA, Guilleminault C. Future perspectives in sleep medicine. Adv Otorhinolaryngol. 2017;80:145-147. doi: 10.1159/000470886.

3. Zhang Y, Duffy JF, De Castillero ER, Wang K. Chronotype, sleep characteristics, and musculoskeletal disorders among hospital nurses. Workplace Health Saf. 2018;66:8-15. doi: 10.1177/2165079917704671

4. Spiegelhalder K, Nissen C, Riemann D. Clinical Sleep-Wake Disorders II: Focus on Insomnia and Circadian Rhythm Sleep Disorders. Handb Exp Pharmacol. 2019;253:261-276. doi: 10.1007/164_2017_40.

5. Vedaa $\varnothing$, Mørland E, Larsen M, Harris A, Erevik E, Sivertsen B, et al. Sleep Detriments Associated With Quick Returns in Rotating Shift Work: A Diary Study. J Occup Environ Med. 2017;59:522527. doi: 10.1097/JOM.0000000000001006.

6. Wickwire EM, Geiger-Brown J, Scharf SM, Drake CL. Shift work and shift work sleep disorder: clinical and organizational perspectives. Chest. 2017;151:1156-72. doi: 10.1016/j.chest.2016.12.007.

7. Ferri P, Guadi M, Marcheselli L, Balduzzi S, Magnani D, Di Lorenzo R. The impact of shift work on the psychological and physical health of nurses in a general hospital: a comparison between rotating night shifts and day shifts. Risk Manag Healthc Policy. 2016;9:203-211. doi: 10.2147/RMHP.S115326.

8. Shao MF, Chou YC, Yeh MY, Tzeng WC. Sleep quality and quality of life in female shift-working nurses. J Adv Nurs. 2010;66:15651572. doi: 10.1111/j.1365-2648.2010.05300.x.

9. Saksvik-Lehouillier I, Bjorvatn B, Magerøy N, Pallesen S. Hardiness, psychosocial factors and shift work tolerance among nurses-a 2-year follow-up study. J Adv Nurs. 2016;72(8):1800-12. doi: 10.1111/jan.12951. 
10. Jung HS, Lee B. Contributors to shift work tolerance in South Korean nurses working rotating shift. Appl Nurs Res. 2015;28(2):150-5. doi: 10.1016/j.apnr.2014.09.007.

11. Sorić M, Golubić R, Milosević M, Juras K, Mustajbegović J. Shift work, quality of life and work ability among Croatian hospital nurses. Coll Antropol. 2013;37:379-384.

12. Anbazhagan S, Ramesh N, Nisha C, Joseph B. Shift work disorder and related health problems among nurses working in a tertiary care hospital, Bangalore, South India. Indian J Occup Environ Med. 2016; 20:35-38. doi: 10.4103/0019-5278.183842.

13. Shochat T, Umphress J, Israel AG. Insomnia in primary care patients. Sleep. 1999; 22(2):S359-365

14. Estryn-Behar M, Kaminski M, Peigne E, Bonnet $N$, Vaichere E, Gozlan $\mathrm{C}$, et al. Stress at work and mental health status among female hospital workers. Br J Ind Med. 1990;47:20-28. doi: 10.1136/oem.47.1.20.

15. Alshahrani SM, Baqays AA, Alenazi AA, Alangari AM, Alhadi AN. Impact of shift work on sleep and daytime performance among health care professionals. Saudi Med J. 2017;38:846-851. doi: 10.15537/smj.2017.8.19025.

16. Korsiak J, Tranmer J, Leung M, Borghese MM, Aronson KJ. Actigraph measures of sleep among female hospital employees working day or alternating day and night shifts. J Sleep Res. 2018;27:e12579. doi: $10.1111 /$ jsr. 12579 .

17. Ghalichi L1, Pournik O, Ghaffari M, Vingard E. Sleep quality among health care workers. Arch Iran Med. 2013;16:100-103. doi: 013162/AIM.0010.

18. Smith L, Mason C. Reducing night shift exposure: a pilot study of rota, night shift and age effects on sleepiness and fatigue. J Hum Ergol. 2001;30:83-87.

19. Duffy JF, Zeitzer JM, Czeisler CA. Decreased sensitivity to phase-delaying effects of moderate intensity light in older subjects. Neurobiol Aging. 2007;28:799-807. doi: 10.1016/j. neurobiolaging.

20. Shields M. Shift work and health. Health Reports 2002;13:11.

21. Chien PL, Su HF, Hsieh PC, Siao RY, Ling PY, Jou HJ. Sleep Quality among Female Hospital Staff Nurses. Sleep Disord. 2013;2013:283490. doi: 10.1155/2013/283490.

22. Shao MF, Chou YC, Yeh MY, Tzeng WC. Sleep quality and quality of life in female shift-working nurses. J Adv Nurs. 2010;66:15651572. doi: 10.1111/j.1365-2648.2010.05300.x.

23. Rutledge T, Stucky E, Dollarhide A, Shively M, Jain S, Wolfson T, et al. A real-timeassessment of work stress in physicians and nurses. Health Psychol. 2009;28:194-200. doi: 10.1037/a0013145. 